\title{
Investigating anogenital distance and antral follicle count as novel markers of fertility within a herd of cows with positive or negative genetic merit for fertility traits
}

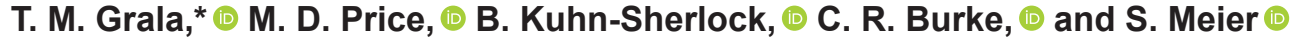 \\ DairyNZ Ltd., Cnr Ruakura and Morrinsville Rds, Newstead, Hamilton 3201, New Zealand
}

\begin{abstract}
Using early-in-life markers of reproductive characteristics may enhance the speed and success of genetic improvement in fertility. We investigated 2 phenotypes that can be measured early in life and are moderately heritable to determine their association with traditional measures of reproductive success and genetic variation under a seasonal-calving, pasture-based system. Cows were bred to be divergent in the New Zealand Fertility Breeding Value, which estimates genetic merit for fertility. Cows consisted of 2 groups with an average positive $(+5 \%)$ or negative $(-5 \%)$ genetic merit for fertility traits and were expected to have large diversity in reproductive outcomes. Calves were genotyped at $41 \pm 3.1 \mathrm{~d}$ of age (mean $\pm \mathrm{SD} ; \mathrm{n}=538$ ), and antral follicle counts (AFC) were measured when they were postpubertal heifers before their first breeding (416 \pm $15 \mathrm{~d}$ old; 92-d range; $\mathrm{n}=520$ ). The anogenital distance (AGD) was measured in 478 primiparous cows of this same population 50 to $60 \mathrm{~d}$ after the breeding start date when they were $881 \pm 25 \mathrm{~d}$ old (145-d range). The AGD was shorter in animals with a positive genetic merit for fertility traits (based on parent averages). An indicator of herd reproductive success in a seasonalcalving system (recalving by $6 \mathrm{wk}$ in lactation 2 ) was chosen for logistic regression with cross-validation, and if significant, a cut-off was calculated that categorized animals into groups. Both linear and quadratic regression was undertaken, and the model with the greatest sensitivity for detection of nonpregnant cows used. The AGD linear model was significant with a sensitivity of $64 \%$ and a specificity of $48 \%$. This model resulted in a cut-off of $102 \mathrm{~mm}$, which we used to classify cows as short $(\leq 102 \mathrm{~mm})$ or long $(>102 \mathrm{~mm})$ AGD animals. Primiparous cows with a short AGD were more likely
\end{abstract}

Received November 24, 2020

Accepted August 9, 2021.

*Corresponding author: talia.grala@dairynz.co.nz to be pregnant within the first 3 and 6 wk of mating, and become pregnant as a primiparous cow, than those with a long AGD. The time from calving to conception was $20 \mathrm{~d}$ earlier in short AGD compared with long-AGD cows. None of the models tested for AFC were significant; therefore cows were categorized into 3 groups based on previous work in seasonal systems. However, associations between fertility phenotypes and AFC group were limited. Genomic regions of interest for AGD and AFC did not overlap, indicating phenotypes were genetically independent. Overall, AGD appears as a promising early marker of fertility in seasonal grazing systems.

Key words: anogenital distance, antral follicle count, conception, genome-wide association study

\section{INTRODUCTION}

Genetic variability that underlies fertility has been recognized as an important pathway for improving dairy cattle reproductive performance. Weightings of fertility traits in breeding objectives have increased over the last 20 yr (Miglior et al., 2005; Cole and Vanraden, 2018). However, the rate of genetic improvement for reproductive performance has been slow (Berry et al., 2014; Pryce et al., 2014), partly because the heritability estimates of conventional reproductive traits are low (Berry et al., 2014; Häggman et al., 2019).

Use of novel markers that are highly correlated with reproductive performance, expressed early in life, and are moderately heritable may support future increases in genetic merit for fertility and thus reproductive performance. Examples are antral follicle count (AFC) and anogenital distance (AGD). Large AFC is associated with greater fertilization rates (Nagai et al., 2015) and greater pregnancy rates (Mossa et al., 2012; Martinez et al., 2016), thought to be due to better follicle health (Ireland et al., 2008). The AFC is variable between cows, but very repeatable within a cow (Burns et al., 2005; Ireland et al., 2007). The heritability for AFC is estimated at 0.25 and 0.31 in US Holstein-Friesian 
heifers and Irish Holstein-Friesian cows, respectively (Walsh et al., 2014).

The AGD is the distance from the center of the anus to clitoris as measured by calipers. It is easier and less invasive to measure than AFC. Anogenital distance was inversely associated with reproductive outcome in Canadian Holstein cows (Gobikrushanth et al., 2017); however, researchers could not determine any association between AGD and reproductive performance in Irish Holstein-Friesians cows (Gobikrushanth et al., 2019). They concluded that the lack of an association may be due to the increased emphasis on genetic improvement for fertility in Ireland in the last $10 \mathrm{yr}$. The heritability of AGD in cattle was reported to be 0.37 (Gobikrushanth et al., 2019), slightly greater than AFC.

Identifying genetic markers associated with these 2 phenotypes could assist in breeding programs. Determination of pathways involved may highlight key networks of genes influencing fertility and prenatal reproductive development. Genetic variation has been identified that is associated with AFC in beef heifers on chromosomes 2, 3, and 23 (Stegemiller et al., 2021). In Nellore cattle, regions of interest included chromosomes 1 and 26, which accounted for 6.2 and $7.3 \%$ of the total additive genetic variance, respectively (Grigoletto et al., 2020). For AGD, strong genetic markers are yet to be reported in cows (Gobikrushanth et al., 2019).

Our team has generated a custom-bred herd of Holstein-Friesian dairy cattle with positive or negative genetic merit for fertility traits as a resource and has followed them from birth through to their third pregnancy (Meier et al., 2021a; 2021b). We hypothesized that the genetic merit for fertility traits would be associated with AFC and AGD; therefore, we investigated these phenotypes in our fertility research herd. Additionally, we investigated the associations between these phenotypes and key reproductive measures, the genetic variation underlying these phenotypes, and the genes and pathways associated with those genetic signals.

\section{MATERIALS AND METHODS}

\section{Animals}

This study was undertaken with ethical approval from the Ruakura Animal Ethics Committee. A group of 565 Holstein-Friesian calves were progeny of a customized breeding program to create a population divergent in genetic merit for fertility traits. The New Zealand Fertility Breeding Value (FertBV) was used to create cows with positive $(\mathbf{P O S} ;+5 \%)$ or negative (NEG; $-5 \%$ ) genetic merit for fertility traits. At the same time, limits were put on the inbreeding coefficient of the offspring $(<12 \%)$ and the expected parent averages for milk volume, fat, protein, BW, and ancestry (\% North American Holstein-Friesian) to ensure groups were within 1 standard deviation and calves were $>15 / 16$ parts Holstein-Friesian as described in Meier et al. (2021a). These calves were followed for over $3 \mathrm{yr}$ to determine influences of the FertBV on puberty (Meier et al., 2021a) and other reproductive phenotypes (Meier et al., 2021b; Figure 1).

\section{Grazing Management}

All calves were reared for 13 wk before being shifted to a grazing property where the heifers were grouped into 4 age-based herds of 130 to 150 heifers, with the POS and NEG heifers represented across grazing herds. Before calving, heifers were shifted to the milking farm and allocated to 2 herds balanced for calving date and FertBV. For lactation 2, cows were managed as 1 herd.

\section{Reproductive Management of the Heifers}

Full details of the heifer breeding are described in Meier et al., (2021a). In brief, weekly plasma sampling for progesterone analysis started when heifers were approximately $190 \mathrm{~kg}$ and continued until puberty was reached. Puberty was defined to have occurred when progesterone concentrations were $>1 \mathrm{ng} / \mathrm{mL}$ in at least 2 of 3 consecutive weekly plasma samples (Macdonald et al., 2007). Heifers $(\mathrm{n}=15)$ that had not reached puberty by $21 \mathrm{~d}$ after the start of seasonal breeding underwent transrectal ultrasonography with a 5 to 15 $\mathrm{MHz}$ probe (SonoScape S6V, Euromed Medical Systems). Heifers that had a corpus luteum (CL) were returned to the herd without treatment, but heifers that were CL-negative $(\mathrm{n}=4)$ had a reproductive treatment to stimulate ovulation. Animals received an intravaginal P4-releasing device (CIDR, Zoetis New Zealand Limited) from 0 to $7 \mathrm{~d}$ (insertion $=\mathrm{d} 0$ ), gonadorelin (Ovurelin $100 \mathrm{mg}$ i.m.; Bomac Laboratories Ltd) on d 0, and $500 \mathrm{mg}$ of cloprostenol i.m. on d 7 (Ovuprost, Bayer Animal Health NZ). All heifers were bred by natural service using Jersey bulls for a 98-d breeding period. Thirty-five 15-mo-old Jersey bulls were comingled with each of the grazing herds at a ratio of 1 bull per 20 heifers (6-8 bulls per group). The remaining bulls were held in reserve to be rotated on a regular basis with weekly bull checks occurring. The heifers were confirmed as pregnant in February 2017 using transrectal ultrasonography with expected calving from July 2017. Fetal aging was undertaken at 3 time points, as described below, to enable accurate pregnancy diagnosis and identify early embryo losses. 
All heifers were examined 49 to $51 \mathrm{~d}$ after the start of the breeding season. Nonpregnant heifers, or those detected with a pregnancy less than $30 \mathrm{~d}$ old, were enrolled for a second pregnancy diagnosis at $79 \mathrm{~d}$ after the start of the breeding season. Confirmation of pregnancy included identification of heartbeat to indicate the presence of a viable fetus. The final pregnancy diagnosis included all heifers and was undertaken $44 \mathrm{~d}$ after bulls were removed (142 d after the start of breeding).

\section{Reproductive Management of the Lactating Cows}

Full details of the breeding and phenotypes are described in Meier et al., (2021b). Estrus detection was performed by visual observation with the aid of paint applied to the tail-head. The seasonal breeding periods for lactation 1 and 2 were 98 and $76 \mathrm{~d}$, respectively.

As lactating cows, the majority of the cows were bred to AI through the entire seasonal breeding pe-

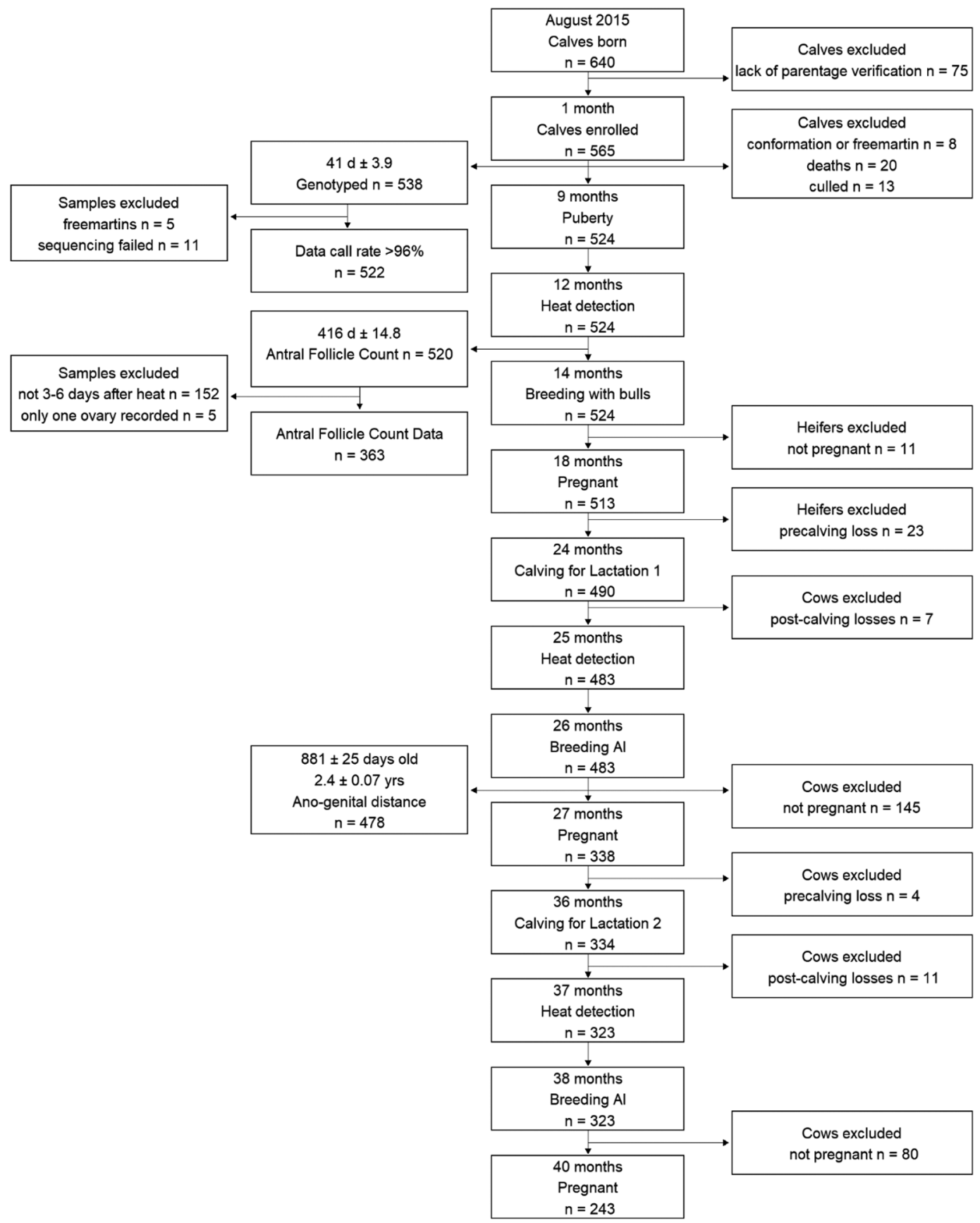

Figure 1. Flow diagram detailing the animals (right-hand side) and samples (left-hand side) available throughout the study. Sampling ages are reported as mean $\pm \mathrm{SD}$. 
riod, except for those cows transiently separated from the main herds into the "sick group" where they were comingled with a Hereford bull. During the first lactation breeding period, POS and NEG FertBV cows were randomly assigned to $\mathrm{AI}$ with sire semen of POS or NEG genetic fertility respectively for the first $63 \mathrm{~d}$, and followed for a further $21 \mathrm{~d}$ of AI with short gestation length semen of no particular genetic fertility ranking (Livestock Improvement Coorporation, 2019). During the second lactation mating, all cows were inseminated using commercially available sire semen selected by the farm manager.

For both lactations, cows not mated in the first 42 $\mathrm{d}$ were examined $44 \mathrm{~d}$ after the start of breeding for the presence of a CL using transrectal ultrasonography with the 5 to $15 \mathrm{MHz}$ probe. Those cows without a CL were synchronized by treatment with a CIDR intravaginal P4-releasing device from d -9 to -2 , gonadorelin (100 mg i.m.) on $\mathrm{d}-9$, and $500 \mathrm{mg}$ of cloprostenol i.m. on $\mathrm{d}-2$. Cows were submitted for AI on $\mathrm{d} 0$ and subsequently on observed estrus.

\section{Pregnancy Diagnoses}

For both lactations, pregnancy diagnosis was undertaken to enable the pregnancies to be aged and to assess fetal losses. Pregnancy was confirmed by the presence of a viable fetus with a heartbeat. Each cow was assessed at 50 to $60 \mathrm{~d}$ after the breeding start date. Those cows not detected pregnant, or with a possible pregnancy $<30 \mathrm{~d}$ old, were enrolled for another pregnancy diagnosis at $\sim 80 \mathrm{~d}$ after breeding start date. A final pregnancy diagnosis including all cows was undertaken 43 to $44 \mathrm{~d}$ after the end of mating by transrectal ultrasonography using the 5 to $15 \mathrm{MHz}$ probe or Esi-Scan using a 3 to 7 $\mathrm{MHz}$ probe (BCF Technologies).

\section{Postpartum Anovulatory Interval Determination}

The postpartum anovulatory interval (PPAI) was determined from progesterone concentrations measured in skim milk collected twice (lactation 1) or once (lactation 2) weekly.

Milk Progesterone Concentrations. Milk progesterone concentrations were determined in milk samples collected from $14 \mathrm{~d}$ postcalving until the first $42 \mathrm{~d}$ of the breeding period was complete. The milk samples were transported to the laboratory at the end of the sampling day and preserved via freezing. Samples were defatted using centrifugation $\left(\right.$ at $4^{\circ} \mathrm{C}, 1,900 \times g$ for 12 min), and the skim milk was harvested. A commercial, double-antibody RIA kit was used to determine skim milk progesterone concentrations in accordance with the manufacturer's instructions (ImmuChem
Progesterone Double Antibody RIA, MP Diagnostics). The inter- and intraassay coefficients of variation were $11.3 \%$ and $7.5 \%$ for a high standard, $11.5 \%$ and $4.3 \%$ for the medium standard, and $12.1 \%$ and $9.2 \%$ for the low standard. The minimal detectable concentration was $0.44 \mathrm{ng} / \mathrm{mL}$.

Determining the Progesterone Cut Point. A cut point of $0.55 \mathrm{ng} / \mathrm{mL}$ for elevated skim milk progesterone content was chosen to indicate absence or presence of a functional CL. This value was chosen after comparing progesterone concentrations in plasma and skim milk taken at the same time point at various stages of the estrous cycle of 20 cows. The relationship (skim milk concentrations $=0.441 \times$ plasma concentrations + $\left.0.1129, \mathrm{R}^{2}=0.83\right)$ indicated $0.55 \mathrm{ng} / \mathrm{mL}$ progesterone in skim milk is equivalent to $1 \mathrm{ng} / \mathrm{mL}$ in plasma (Meier et al., 2021b).

Determining the PPAI. In lactation 1, the date of ovulation was defined as the sample day when 2 consecutive or 2 of 3 skim milk progesterone concentrations were $>0.55 \mathrm{ng} / \mathrm{mL}$ (Meier et al., 2021b). With weekly samples in lactation 2 , the date of ovulation was defined as the date of milk sampling when skim milk progesterone concentrations were $>0.55 \mathrm{ng} / \mathrm{mL}$ and when there was a pattern of elevated skim milk progesterone concentrations in the subsequent samples. The PPAI was the difference between calving date and ovulation date. Cows whose skim milk progesterone concentrations had not been elevated by the end of the progesterone sample regimen (38-39 d after the start of breeding) were right-censored with the censored PPAI as days between calving to the start of breeding $+39 \mathrm{~d}$.

\section{Genotypes}

Genotyping of calves in the herd $(41 \pm 3.9 \mathrm{~d}$ of age, mean $\pm \mathrm{SD} ; \mathrm{n}=538$; Figure 1 ) was performed by GenomNZ (AgResearch) using the GeneSeek GGP Bovine 150K SNPchip (Illumina). Genotyping failed for 15 animals, of which 4 were freemartins. Data from a fifth freemartin were manually removed. The remaining 522 animals had data with a $\geq 96 \%$ call rate. A total of 138,974 SNPs were genotyped, and then any SNPs having $\geq 5 \%$ missingness were excluded, leaving 136,454 SNPs. A minor allele frequency threshold of $\geq 1 \%$ was applied to the data, resulting in approximately 128,400 SNPs for analysis.

\section{Antral Follicle Count}

Antral follicle counts were targeted to be measured 3 to $6 \mathrm{~d}$ after detection of activity-based estrus before a heifer's first breeding, when they were approximately 12 to 14 mo of age $(\mathrm{n}=520$, Figure 1$)$. The activity- 
based estrus was identified using the manufacturer's algorithm ("system heat") for a collar-mounted activity device (Heatime, SCR Engineers Ltd.), which was used on every heifer. This approach resulted in $70 \%(\mathrm{n}=$ 363) of measures occurring within 3 to $6 \mathrm{~d}$ after a system heat, enabling the measurement of the peak AFC of the first follicular wave (Ireland et al., 2011). The remaining $30 \%(\mathrm{n}=152)$ of the measures were not used (Figure 1) because a 7 -fold variation in follicle number during an estrous cycle has been previously reported (Burns et al., 2005). Each heifer underwent transrectal ultrasonography using the 5 to $15 \mathrm{MHz}$ probe, with images stored for later analysis. Each ovary was identified and scanned in a manner that allowed a complete sweep through the ovary. All follicles $\geq 2 \mathrm{~mm}$ in both ovaries were counted and summed to give the AFC per heifer. Two operators undertook all counts, with 99 heifers counted by both operators. The average AFC among those 99 heifers was 23.2 and 21.7 (standard error of the difference $=0.845$ ) for operator $\mathrm{A}$ and $\mathrm{B}$ and had a correlation of 0.72 .

\section{Anogenital Distance}

Anogenital distance was measured with calipers as detailed by Gobikrushanth et al., (2017). Briefly, measures were undertaken when cows were approximately 2.2 to $2.6 \mathrm{yr}$ of age and coincided with pregnancy diagnosis (Figure 1). Anogenital distance was defined as the distance from the center of the anus to the base of the clitoris and was measured using stainless-steel digital calipers. Bodyweight was measured every $2 \mathrm{wk}$, and the measure taken closest to the AGD measure was used as the BW at the time of AGD $(r=0.12)$.

\section{Analyses and Descriptions}

Phenotypic data analysis was performed using SAS/ STAT 15.1 (SAS Institute Inc.). A binary indicator of seasonal reproductive performance (i.e., whether or not she calved within the first 6 wk of the calving period in her second lactation) was generated for each of the animals in the phenotypic data set. This indicator was chosen as it is routinely used by NZ dairy farmers as a key indicator of reproductive performance in seasonal dairying, and we wanted to determine if improvements could be made to reproductive indicators used by farmers. Binary logistic regression (Proc Logistic) was used to test both linear and quadratic effects of the 2 phenotypes on the likelihood of the animal not calving within the first 6 wk of the calving period in her second lactation, and the performance of each model was evaluated using a "leave-one-out" cross-validation approach followed by a receiver operator characteristic curve option to investigate if AGD or AFC had predictive value. If significant, linear and quadratic models were compared to determine which model was more sensitive for detecting nonpregnant cows. The successful model was then used to predict sensitivity and specificity for each AGD (based on actual and predicted probability of being pregnant). The AGD with the greatest Youden's Index (sum of sensitivity and specificity minus 1) was used as the cut-off. The cut-off was used to categorize cows into groups, which was desired to provide a usable output. The potential use, particularly of AGD (which could be easily measured on farm), would be improved by having a target measure for farmers or rural professionals to make decisions on heifer replacements.

We used ANOVA (Proc Mixed) to test the effect of genetic merit of fertility traits (FertBV) on AFC and AGD, and Pearson correlation analysis (Proc Corr) was used to determine if there was a linear relationship between AFC and AGD. Once the cows were assigned phenotypic groupings based on the cut-offs, binary logistic regression (Proc Glimmix) was used to analyze binary reproductive outcomes, and survival analysis was performed for continuous reproductive outcomes (Cox proportional hazard model, Proc PHReg). The models included fertility group or potential early-in-life marker as fixed effects, sire as a random effect (except for the heifer phenotypes of final pregnancy rate and pregnancy within 6 wk of mating), and age at measurement, BW at measurement, and season calving day as covariates. Season calving day is the calving date as the number of days after June 1 . The Cox proportional hazard model included a censoring variable for animals without a submission or conception date. Significance was declared if $P \leq 0.05$, with a trend reported if 0.05 $<P \leq 0.10$.

\section{GWAS and Pathway Analysis}

Genome-wide efficient mixed-model association (GEMMA; Zhou and Stephens, 2012) was used to fit a univariate linear mixed model per phenotype per SNP $i$ of the following form:

$$
\mathbf{Y}=\mathbf{W} \mathbf{\alpha}+\mathbf{x} \beta_{i}+\mathbf{u}+\varepsilon,
$$

where $\mathbf{Y}$ is the $n \times 1$ vector of phenotypes with $n$ being the sample size; $\mathbf{W}$ is the $n \times c$ incidence matrix of $c$ covariates with $\boldsymbol{\alpha}$ being the $c \times 1$ vector of corresponding coefficients (described at the end of the paragraph); $\mathrm{x}$ is the $n \times 1$ vector of SNP genotypes with $\beta$ being the corresponding coefficient (SNP effect size); $\mathbf{u}$ is the $n \times$ 1 vector of animal additive genetic effects; and $\varepsilon$ is the $n \times 1$ vector of residuals. The assumed covariate structures are $\operatorname{MVN}_{n}\left(0, \lambda \sigma_{\varepsilon}^{2} \mathbf{K}\right)$ for $\mathbf{u}$, and $\operatorname{MVN}_{n}\left(0, \sigma_{\varepsilon}^{2} \mathbf{I}_{n}\right)$ for 
$\varepsilon$, where $\mathrm{MVN}_{n}$ denotes an $n$-dimensional multivariate normal distribution; $\lambda$ is the variance component ratio; $\sigma_{\varepsilon}^{2}$ is the residual variance; $\mathbf{K}$ is the $n \times n$ genomic relationship matrix; and $\mathbf{I}_{n}$ is an $n \times n$ identity matrix. The genomic relationship matrix $\mathbf{K}$ was built from all SNP information using a native GEMMA function. Variance components were estimated using a restricted maximum likelihood average information algorithm in GEMMA to determine standard errors for both random effects. Covariates included management group $(1,2,3$, or 4) to account for the group that an animal belonged to at the time the phenotype was recorded. For AFC, estrous stage was used to account for day of measurement, and for AGD, the BW closest to AGD was used to account for growth effects. False-discovery rate control was performed using a chromosome-wise false-discovery rate of 0.05 .

\section{Biological Pathway Analysis Using MAGMA}

Pathway analysis used MAGMA (version 1.07; de Leeuw et al., 2015) and followed 3 steps. First, where possible, SNPs were annotated to the nearest gene using a boundary extended by $7 \mathrm{~kb}$ outside the transcription start and end sites of the gene, using bovine gene location (UMD3.1) from ensemble-biomaRt (https:// www.ensembl.org/biomart/martview). This annotation pipeline assigned 65,448 SNPs and resulted in a total of 22,429 genes being represented by 1 or more SNP. Second, a gene-based analysis step used $P$-values from the GWAS GEMMA output, and third, a geneset analysis determined associated pathways with AFC and AGD using the $\mathrm{C} 2$ : curated gene sets or the C5: Gene Ontology (GO) gene sets available from MSigDB Collections (https://www.gsea-msigdb.org/gsea/ msigdb/collections.jsp). All analyses in MAGMA are structured as a linear regression model on gene-level data as follows:

$$
Z=\beta_{0}+\beta_{1} \mathrm{G}_{1}+e,
$$

where $Z$ was the phenotype vector; gene sets $\mathrm{G}_{1}$ were binary indicator variables, coded with "1" for genes in the gene-set, and with " 0 " otherwise; and $e$ was the residual vector. The intercept $\beta_{0}$ represents the mean, and $\beta_{1}$ the association specific to the gene-set 1 .

\section{RESULTS}

\section{Generating Cut-Points for AFC and AGD}

Neither the linear or quadratic logistic models were significant for AFC (Table 1); therefore, cut-points were identified in the literature (Burns et al., 2005; Ireland et al., 2007, 2008; Mossa et al., 2010) and used to enable comparison to previous studies. Animals were divided into the following 3 groups: low ( $\leq 15$ follicles; $11.8 \pm$ 2.87 , mean $\pm \mathrm{SD} ; \mathrm{n}=57)$, intermediate $(16-24$ follicles; $20.3 \pm 2.69$, mean $\pm \mathrm{SD} ; \mathrm{n}=133 ;)$, and high $(\geq 25$ follicles; $35.0 \pm 9.10$, mean $\pm \mathrm{SD} ; \mathrm{n}=173$ ). Both the linear and quadratic logistic models were significant for AGD; however, the linear model had a greater sensitivity than the quadratic model. This greater sensitivity results in a greater number of nonpregnant cows being correctly identified, which is preferred to identifying pregnant cows correctly (specificity). Using the linear model, the AGD cut point was determined to be 102 $\mathrm{mm}$. Reassigning cows based on this cut-off resulted in 304 short-AGD $(93 \pm 6.3 \mathrm{~mm}$, mean $\pm \mathrm{SD})$ and 174 long-AGD cows $(108 \pm 5.2 \mathrm{~mm}$, mean $\pm \mathrm{SD})$.

\section{$A F C$ and $A G D$}

The AGD values were normally distributed, whereas the AFC distribution was slightly skewed (Table 2). The 2 phenotypes were not correlated with each other (AGD and AFC, $\mathrm{r}=-0.025, P=0.66$ ). Cows with a POS FertBV had shorter AGD (98.0 vs. $99.8 \mathrm{~mm} ; P=$ $0.040)$ but similar AFC (26.9 vs $25.0 ; P=0.12)$ to cows with a NEG FertBV.

There were no significant associations between binary reproductive measures across the 3 consecutive years and AFC (Table 3). As primiparous animals, the PPAI was associated with AFC group (Table 4; $P=0.041$ ), but not in a linear manner. Cows with a low AFC had the shortest median PPAI compared with those of an intermediate AFC (21.5 d vs. 24.5 d), with high AFC cows having a median PPAI of $22.2 \mathrm{~d}$.

In their first lactation, a greater proportion of cows with short AGD became pregnant within the first 3 and 6 wk of mating compared with long-AGD cows (Table $5 ; 44 \%$ vs. $28 \%, P=0.002 ; 55 \%$ vs. $38 \%, P=$ 0.003 , respectively). The median interval from calving to conception and planned start of mating to conception was $20 \mathrm{~d}$ and $22 \mathrm{~d}$ shorter for the cows with short AGD, respectively (Table 4; Figure 2). The proportion of cows that were pregnant in lactation 1 was greater $(P=0.038$; Table 4$)$ in short-AGD cows, with $77 \%$ of the cows pregnant versus $67 \%$ of long-AGD cows pregnant at the final pregnancy test. The proportion of cows that recalved within 6 wk of the calving period in lactation 2 was also different $(P=0.001)$ between groups, with $52 \%$ of short-AGD cows versus $34 \%$ of long-AGD cows achieving this milestone. The linear regression resulted in an average $9 \%$ probability increase of recalving within $6 \mathrm{wk}$ in the second lactation for every 5-mm decrease in AGD. 
Table 1. Binary logistic regression of antral follicle count $(\mathrm{AFC})^{1}$ and anogenital distance (AGD $)^{2}$ on whether a cow recalved in the first $6 \mathrm{wk}$ of her second lactation; both linear and quadratic models were tested, followed by a receiver operator characteristic curve (ROC) option to investigate whether AFC or AGD had predictive value [area under the curve $(\mathrm{AUC})>0.5$ ]

\begin{tabular}{|c|c|c|c|c|}
\hline \multirow[b]{2}{*}{ Item } & \multicolumn{2}{|c|}{$\mathrm{AFC}$} & \multicolumn{2}{|c|}{ AGD } \\
\hline & Linear & Quadratic & Linear & Quadratic \\
\hline Odds ratio & 0.992 & 1.000 & 1.034 & 1.002 \\
\hline $95 \%$ CI & $0.976-1.008$ & $0.999-1.001$ & $1.014-1.055$ & $1.000-1.003$ \\
\hline$P$-value & 0.30 & 0.80 & $<0.001$ & 0.023 \\
\hline ROC AUC & & & 0.587 & 0.588 \\
\hline Sensitivity, \% & & & 63.8 & 48.0 \\
\hline Specificity, \% & & & 48.3 & 68.1 \\
\hline False positive, $\%$ & & & 43.3 & 38.5 \\
\hline False negative, $\%$ & & & 44.3 & 44.8 \\
\hline
\end{tabular}

${ }^{1} \mathrm{AFC}$ was measured when animals were $416 \pm 15 \mathrm{~d}$ old (mean $\pm \mathrm{SD}$ ) as breeding-age heifers.

${ }^{2} \mathrm{AGD}$ was measured when animals were $881 \pm 25 \mathrm{~d}$ old (mean $\pm \mathrm{SD}$ ) as primiparous cows, 50 to $60 \mathrm{~d}$ after the start date of the second breeding period.

\section{GWAS and Pathway Analysis}

From the GWAS for AFC, 1 SNP was significant at a Benjamini-Hochberg-corrected 5\% chromosome-wise significance threshold and the model was unbiased (Figure 3). This SNP (BTA-31115-no-rs; $P=6.15 \times$ $10^{-6}$ ) is located on chromosome 30 and is in NLGN4X. Pathway analysis did not identify significant pathways; however, the top pathway $(P=0.0002)$, REACTOME_ CROSS_PRESENTATION_OF_PARTICULATE_ EXOGENOUS_ANTIGENS _PHAGOSOMES, contains 8 genes related to the internalization of antigens by phagosomes for immune recognition, of which 7 had $P$-values available in the current data set. Output from MAGMA for GO terms associated with AFC was also not significant (top 5 GO terms in Supplemental Table $\mathrm{S} 1$, https://data.mendeley.com/datasets/tfzwx7j8yx/1; Grala, 2021).

From the GWAS for AGD, a single SNP was significant at a Benjamini-Hochberg-corrected $5 \%$ chromosome-wise significance threshold (Figure 3). The model did not appear biased (QQ plot; Figure 3), providing confidence in this result. This SNP (ARSBFGL-NGS-11309; $\left.P=3.66 \times 10^{-6}\right)$ is located on

Table 2. Descriptive statistics and distribution of antral follicle count (AFC) and anogenital distance (AGD) in Holstein-Friesian cattle

\begin{tabular}{|c|c|c|}
\hline Item & $\mathrm{AFC}, \mathrm{n}$ & $\mathrm{AGD}, \mathrm{mm}$ \\
\hline $\mathrm{n}$ & 515 & 478 \\
\hline Age at measurement $\pm \mathrm{SD}$ & $416 \pm 15 \mathrm{~d}$ & $881 \pm 25 \mathrm{~d}$ \\
\hline Min & $\begin{array}{r}5 \\
75\end{array}$ & $\begin{array}{r}69.25 \\
12486\end{array}$ \\
\hline $\begin{array}{l}\text { Max } \\
\text { Mean }+ \text { SD }\end{array}$ & $26.1+10.98$ & $\begin{array}{c}124.86 \\
98.9+9.40\end{array}$ \\
\hline Kurtosis ${ }^{1}$ & 1.26 & 0.12 \\
\hline
\end{tabular}

${ }^{1}$ Kurtosis is an indicator of outliers. A normal distribution has a kurtosis of 0 .

Journal of Dairy Science Vol. 104 No. 12, 2021 chromosome 26 and is $14 \mathrm{~kb}$ upstream from 2 genes, PCGF6 and TAF5. Pathway analysis did not identify significant pathways after multiple testing correction was applied. The top pathway $\left(P=3.13 \times 10^{-5}\right)$, BAE_BRCA1_TARGETS_DN, contains 32 genes related to oxidative stress and cell repair, of which 26 had $P$-values available in the current data set. Output from MAGMA for GO terms associated with AGD was also not significant (top 5 terms in Supplemental Table S1; Grala, 2021).

\section{DISCUSSION}

Two early-in-life phenotypes, AFC and AGD, were studied in cows divergent in their genetic merit for fertility traits, of which AGD differed between cows of a NEG FertBV and those with a POS FertBV. The AGD cut-off generated groups of cows that differed in reproductive outcomes; however, this was not the case for AFC.

The AGD showed the most promise as an easy-to-measure marker of future reproductive success. Distribution of AGD was normal and variable, comparable with previous studies in Canadian Holstein and Irish HolsteinFriesian cows (Gobikrushanth et al., 2017, 2019). The final cut-off for AGD was based on recalving within 6 wk of the calving period in lactation 2 (DairyNZ, 2018). This routinely-used indicator of reproductive success in seasonal dairying was chosen to determine if use of the AGD cut-off would result in improvements to reproductive indicators used by farmer. Gobikrushanth et al., (2017) focused on pregnancy to first insemination and pregnancy by 250 DIM and reported that every 1-mm increase in AGD reduced the likelihood of pregnancy to the first insemination by $3.4 \%$ in first-parity cows. They also report the likelihood of pregnancy was $32 \%$ greater in short-AGD cows compared with long-AGD 
Grala et al.: ANOGENITAL DISTANCE, ANTRAL FOLLICLE COUNT, AND FERTILITY

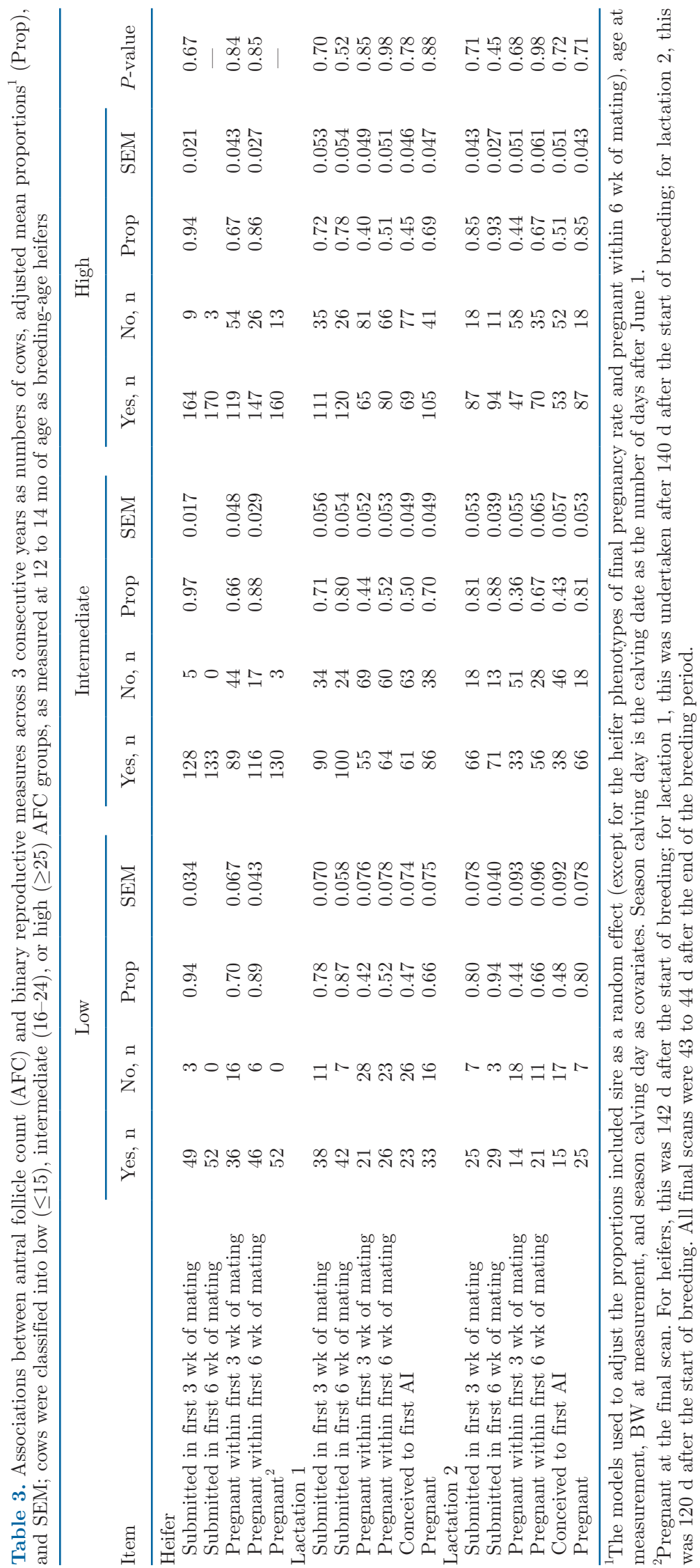


Grala et al.: ANOGENITAL DISTANCE, ANTRAL FOLLICLE COUNT, AND FERTILITY

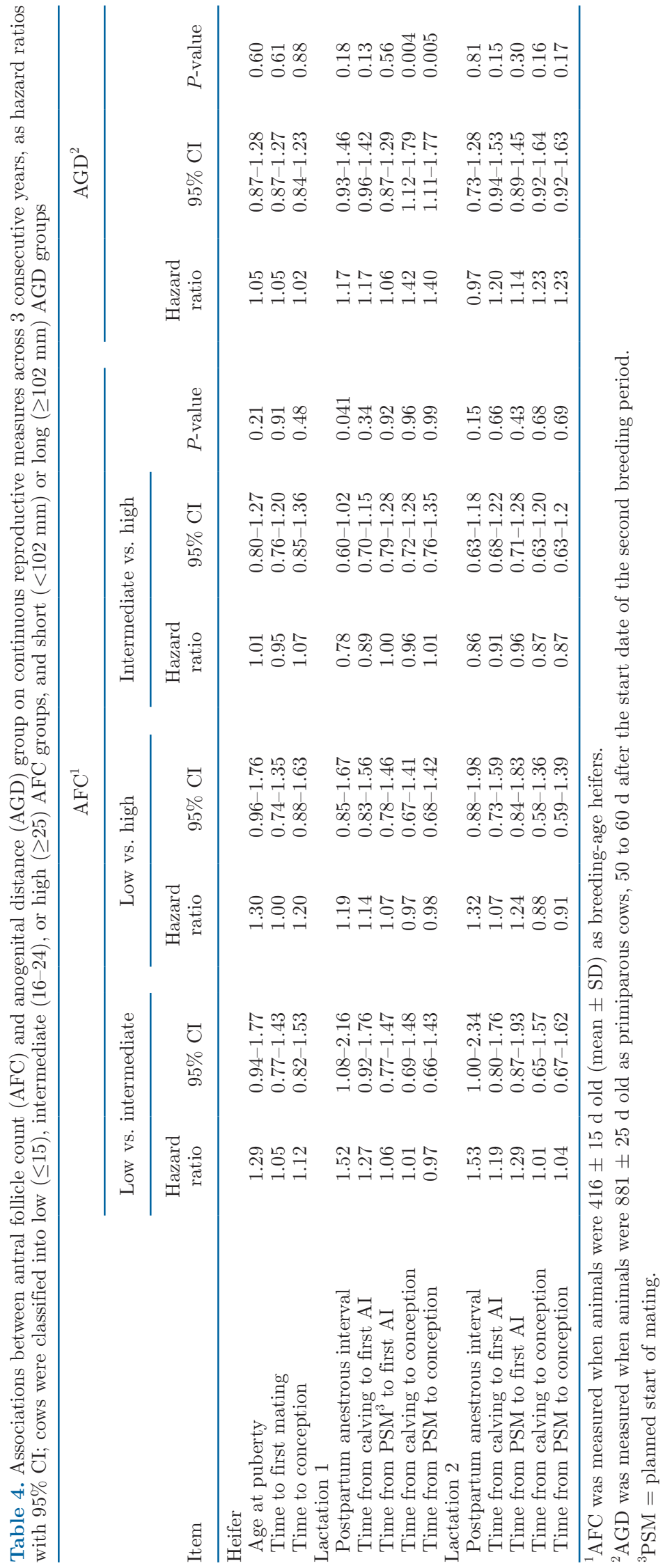


Grala et al.: ANOGENITAL DISTANCE, ANTRAL FOLLICLE COUNT, AND FERTILITY

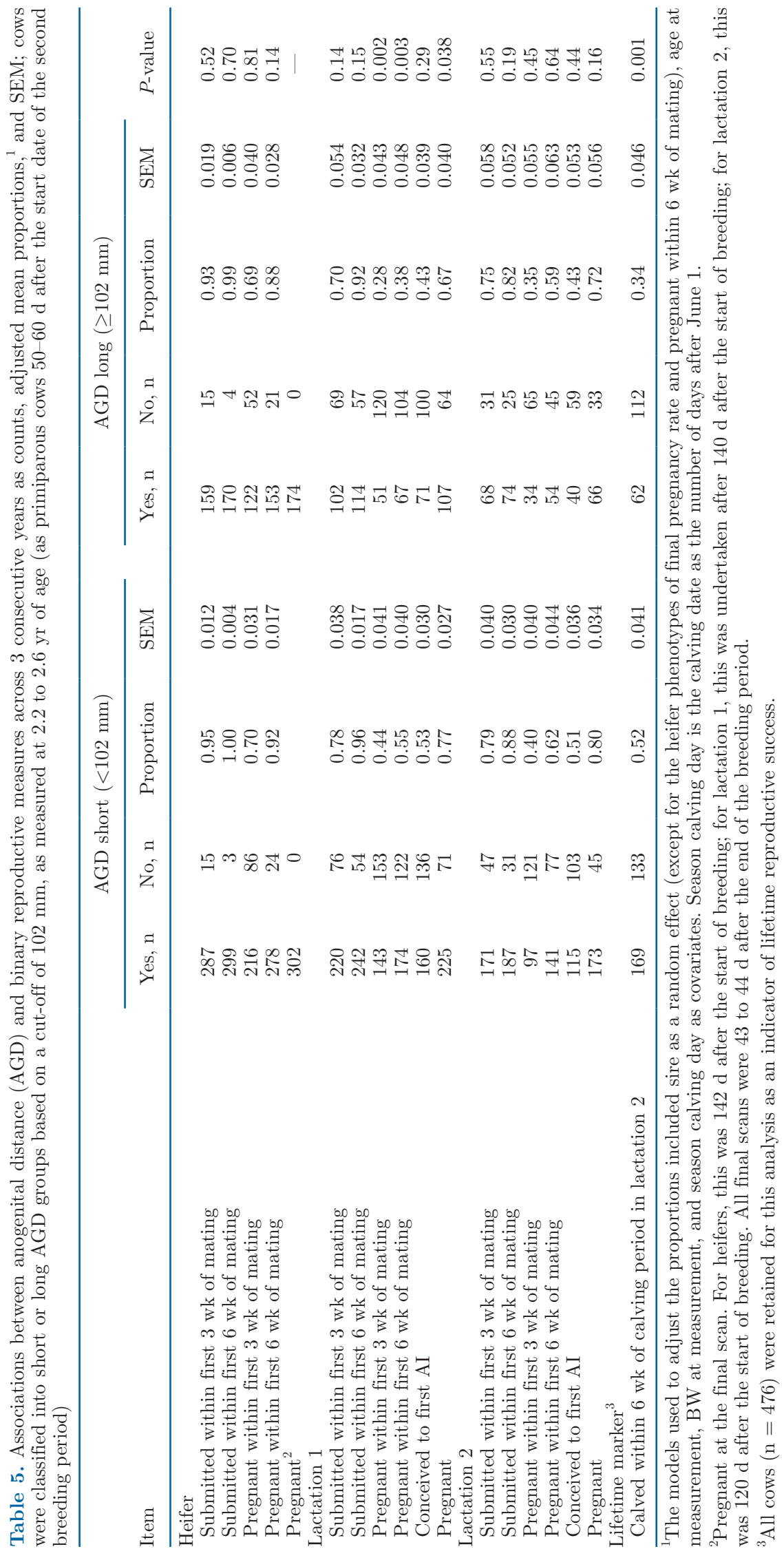



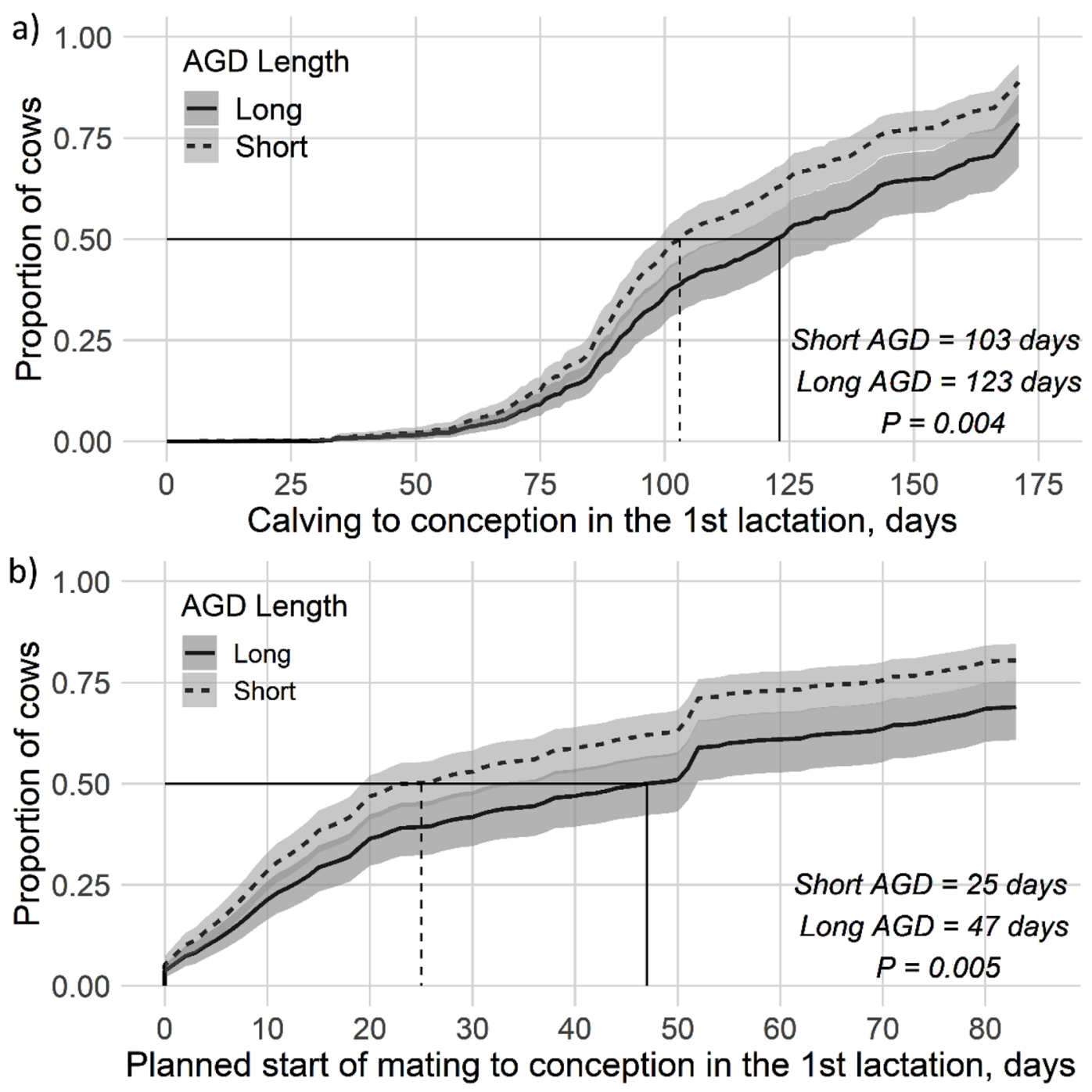

Figure 2. Cumulative incidence curves during the first lactation for cows classed as having a short $(<102 \mathrm{~mm})$ or long $(\geq 102 \mathrm{~mm})$ anogenital distance (AGD). (a) Interval from calving to conception and (b) interval from the planned start of mating to conception. The gray shading is the $95 \%$ CI. The interval when the first $50 \%$ of the group reached the event endpoint is depicted on the graphs.

cows. Although we did not report any differences in the proportions of cows conceiving, every 5 -mm increase in AGD reduced the likelihood of recalving in the first 6 wk of a cow's second lactation by $9 \%$. Additionally, during the cows first lactation, the short-AGD cows were $42 \%$ more likely to be pregnant by the end of the 6 -wk breeding period. Therefore, despite a different reproductive endpoint chosen to determine the cut point, the magnitude of the results is similar between Gobikrushanth et al. (2017) and the current work, indicating short-AGD cows have greater conception and pregnancy probabilities. Interestingly, the time from calving to submission was similar; however, the median time from calving to conception was $20 \mathrm{~d}$ earlier, indicating the processes controlling conception are associated more with AGD than the processes linked to sub- mission (e.g., heat detection). Based on this result, we hypothesize that physiological mechanisms link short AGD and a cow's ability to conceive. Longer AGD are associated with a poorer ovarian response during controlled ovarian stimulation in women (Fabregues et al., 2018). Therefore, future work could test if cows with shorter AGD are also more responsive to gonadotropins or if another mechanism is behind the shorter duration to conception. Pregnancy rates were greater during the first lactation, but not significantly so in the second lactation in short-AGD cows, which may be the result of a reduction in the population size. By the second lactation, the cow numbers had decreased to 338 from the original 513 pregnant heifers. The stronger association in younger cows is similar to the results reported by Gobikrushanth et al., (2017) where short-AGD cows 
had a greater likelihood of pregnancy by 250 DIM compared with longer AGD cows. The difference was significant in primiparous cows but was a tendency in second parity cows, and they also report a difference in population size from 360 compared with only 256 second-parity animals. We cannot conclude from this data whether the effect of AGD is only indicative of reproductive success in earlier lactations or whether effects would be reported in a larger population of cows. In Irish Holstein-Friesians, no difference was reported in submission rate or pregnancy rate (Gobikrushanth et al., 2019) between cows divided into quartiles based on their AGD. The variability of the Irish cows in their genetic merit for fertility was not reported; therefore, it is possible that the large divergence in genetic merit for fertility traits of the animals in our current study has enabled us to detect a significant association. Overall, the strong association of AGD with reproductive outcomes supports the potential use of AGD as a marker of reproductive success.
Heifers with a larger AFC did not have better reproductive performance during the 3 -yr study period. This was unexpected, as AFC has been associated with many predictors of fertility including a better response to superovulation procedures and a greater number of transferable embryos per animal (Ireland et al., 2007). Reduced pregnancy rates have been reported in beef heifers with an AFC less than 15, but no difference was found between those with an AFC of 16 to 29 and those with an AFC of 30 and above (Sanderson and Robertson, 2017). A study in Irish Holstein-Friesians classified cows as low $(\leq 15)$, intermediate $(16-24)$, or high $(\geq 25)$; they reported a longer interval from calving to conception and lesser pregnancy rates to first service for cows with a low AFC, but no differences between cows of intermediate or high AFC (Mossa et al., 2012). The only phenotype in which we reported an association with AFC was the PPAI after first calving where cows with a low or high AFC had shorter median PPAI than those with an intermediate AFC; therefore, there was

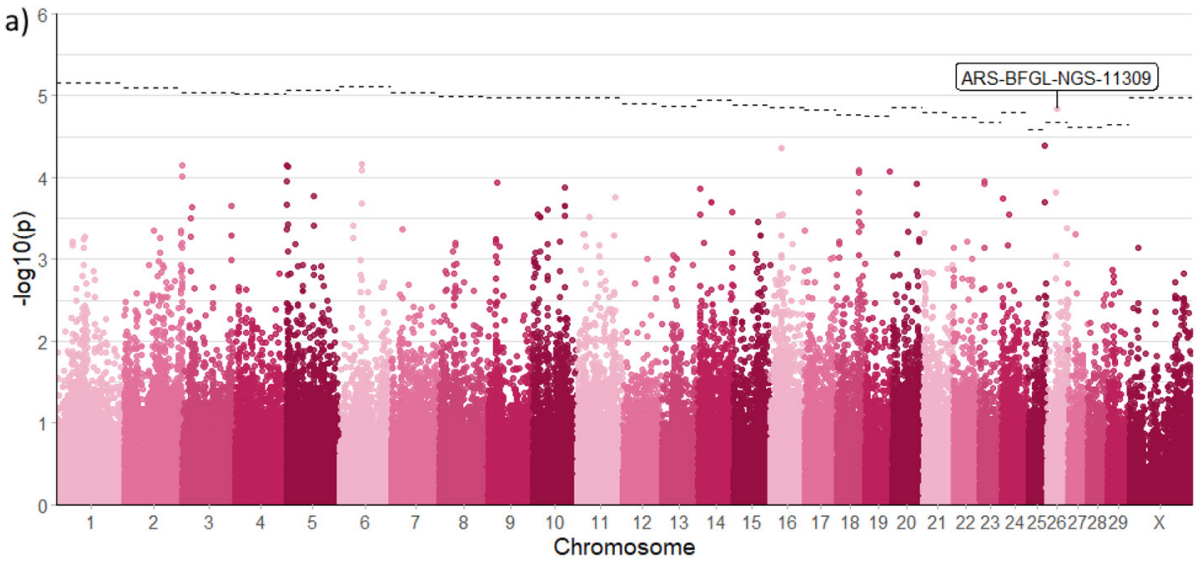

b)
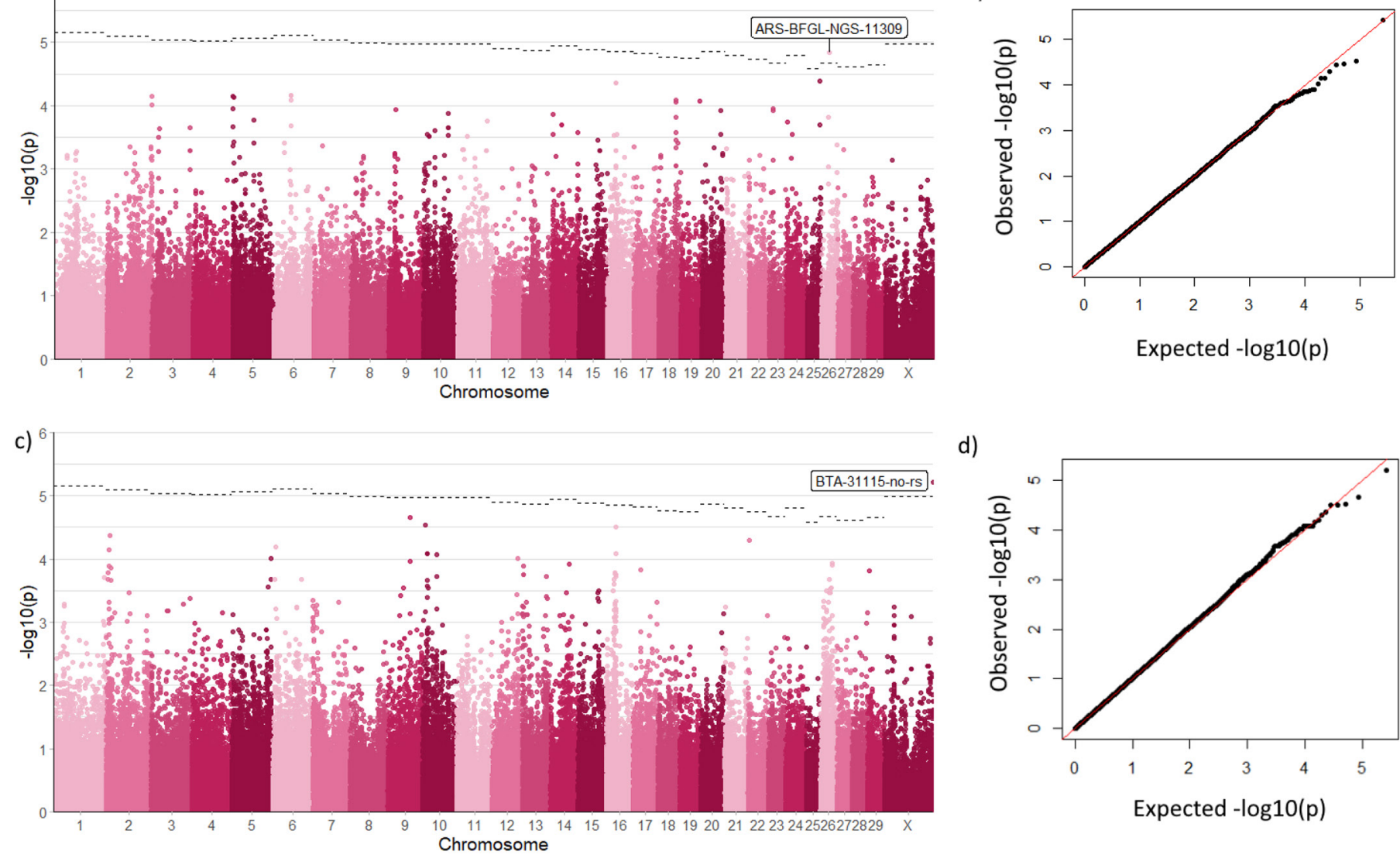

d)

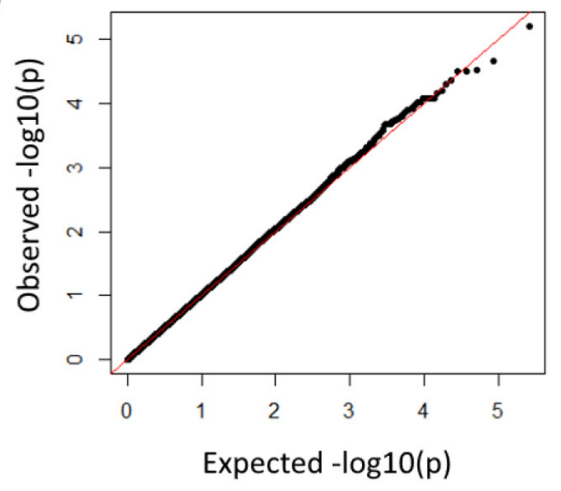

Figure 3. Genome-wide association analysis. (a) Manhattan plot for anogenital distance (AGD), (b) QQ plot for AGD, (c) Manhattan plot for antral follicle count (AFC), (d) QQ plot for AFC. The dotted line indicates chromosome-wise $5 \%$ false-discovery rate, and SNPs above this line are annotated. 
not a negative effect of low AFC in this population. It is possible that $\mathrm{AFC}$ is not a primary limiting factor for reproduction in this fertility animal model, and other influences such as age at puberty, the number of heats before mating, or estrous strength play a more important role (Wathes et al., 2014; Veronese et al., 2019). Use of a strongly associated marker of AFC (hormonal or genetic) may be an approach in breeding for fertility gains by increasing AFC if desired.

The number of cows used in this study is insufficient to estimate the heritability of AGD and AFC; however, it enabled us to undertake preliminary genetic analysis to determine the direction of future work. The single significant SNP in the AGD analysis is $14 \mathrm{~kb}$ upstream of 2 genes, $P C G F 6$ and TAF5. Recent work in mice has shown that $P C G F 6$ plays an essential role in embryonic development, and it colocalizes with histone methyltransferases and deacetylases, epigenetically mediating gene transcription (Liu et al., 2020). The other gene, $T A F 5$, is 1 of $13 T B P$-associated factors that comprise the transcription factor II D (a core transcription factor; Antonova et al., 2019). However, any links of this marker and these genes to AGD needs validation and further study in a larger pool of cows. Using AGD as an early marker of fertility may require the physical measurement of cows, rather than using a genomic marker, particularly if epigenetics and the uterine environment alter AGD. The AFC GWAS identified 1 significant SNP in the X-chromosome. This SNP lies within $N L G N 4 X$, a neuronal cell surface protein with links to autism and Asperger syndrome. None of the regions identified in the current study overlap with other AFC GWAS results, although only literature reports for beef (Stegemiller et al., 2021) or Nellore cattle could be found (Oliveira Júnior et al., 2019; Grigoletto et al., 2020). The potential of a genomic marker for $\mathrm{AFC}$ is useful, as measuring AFC is time consuming and difficult in a nonresearch capacity. The absence of any crossover of chromosomal areas of interest between AGD and AFC, and the lack of association between AGD and AFC indicate that the AGD is unlikely to be an indicator of ovarian reserve, and the 2 markers could be used in combination to increase the fertility of dairy cattle.

\section{CONCLUSIONS}

Primiparous cows with a short AGD were more likely to be pregnant within the first 6 wk of mating, and the duration from calving to conception was $20 \mathrm{~d}$ earlier in short AGD compared with long-AGD cows. Genomewide association studies indicated candidate regions for both AFC and AGD, which could be beneficial because current measures for these phenotypes are time and re- source consuming. Genomic regions of interest for AGD and AFC did not overlap, indicating the phenotypes were independent.

\section{ACKNOWLEDGMENTS}

We acknowledge the invaluable support of the DairyNZ Ltd. (Hamilton, New Zealand) technical and farm teams that supported the data collection for this study. Stuart Morgan, Kate Watkins, Angela Sheahan (Dairy NZ, Hamilton, New Zealand), and Francis Williamson (AgResearch, Hamilton, New Zealand) were pivotal in the phenotyping. The management and farm team at AgResearch's Tokanui Research Farm (Tokanui, New Zealand) supported this work by managing the animals. Livestock Improvement (LIC, Hamilton, New Zealand) and New Zealand Animal Evaluation Limited provided data for this study. This work was made possible through an 8-yr partnership program funded by dairy farmers through DairyNZ Incorporated with matched co-funding from the Ministry of Business, Innovation and Employment (DRCX1302) and aligned core funding from AgResearch (Hamilton, New Zealand). Other support and resources were provided by Fonterra, LIC, and CRV Ambreed (Hamilton, New Zealand). We gratefully acknowledge the dairy farmers that contributed to the establishment of this research herd through their involvement in the contract breeding program to generate the animals. The authors have not stated any conflicts of interest.

\section{REFERENCES}

Antonova, S. V., J. Boeren, H. T. M. Timmers, and B. Snel. 2019 Epigenetics and transcription regulation during eukaryotic diversification: The saga of TFIID. Genes Dev. 33:888-902. https://doi .org/10.1101/gad.300475.117.

Berry, D. P., E. Wall, and J. E. Pryce. 2014. Genetics and genomics of reproductive performance in dairy and beef cattle. Animal 8:105-121. https://doi.org/10.1017/S1751731114000743.

Burns, D. S., F. Jimenez-Krassel, J. L. Ireland, P. G. Knight, and J. J. Ireland. 2005. Numbers of antral follicles during follicular waves in cattle: Evidence for high variation among animals, very high repeatability in individuals, and an inverse association with serum follicle-stimulating hormone concentrations. Biol. Reprod. 73:54-62. https://doi.org/10.1095/biolreprod.104.036277.

Cole, J. B., and P. M. Vanraden. 2018. Symposium review: Possibilities in an age of genomics: The future of selection indices. J. Dairy Sci. 101:3686-3701. https://doi.org/10.3168/jds.2017-13335.

DairyNZ 2018. Fertility Focus Report. Accessed Sep. 2021. https:/ /www.dairynz.co.nz/animal/reproduction-and-mating/improving -reproductive-performance/fertility-focus-report/.

de Leeuw, C. A., J. M. Mooij, T. Heskes, and D. Posthuma. 2015. MAGMA: Generalized gene-set analysis of GWAS data. PLOS Comput. Biol. 11:e1004219. https://doi.org/10.1371/journal.pcbi .1004219 .

Fabregues, F., I. Gonzalez-Foruria, J. Peñarrubia, and F. Carmona. 2018. Ovarian response is associated with anogenital distance in patients undergoing controlled ovarian stimulation for IVF. Hum. Reprod. 33:1696-1704. https://doi.org/10.1093/humrep/dey244. 
Gobikrushanth, M., T. C. Bruinjé, M. G. Colazo, S. T. Butler, and D. J. Ambrose. 2017. Characterization of anogenital distance and its relationship to fertility in lactating Holstein cows. J. Dairy Sci. 100:9815-9823. https://doi.org/10.3168/jds.2017-13033.

Gobikrushanth, M., D. C. Purfield, J. Kenneally, R. C. Doyle, S. A. Holden, P. M. Martinez, E. R. Canadas, T. C. Bruinjé, M. G. Colazo, D. J. Ambrose, and S. T. Butler. 2019. The relationship between anogenital distance and fertility, and genome-wide associations for anogenital distance in Irish Holstein-Friesian cows. J. Dairy Sci. 102:1702-1711. https://doi.org/10.3168/jds.2018-15552.

Grala, T. 2021. AGD and AFC GO terms. Mendeley Data, V1. https: //doi.org/10.17632/tfzwx7j8yx.1.

Grigoletto, L., M. H. A. Santana, F. F. Bressan, J. P. Eler, M. F. G. Nogueira, H. N. Kadarmideen, P. S. Baruselli, J. B. S. Ferraz, and L. F. Brito. 2020. Genetic parameters and genome-wide association studies for anti-müllerian hormone levels and antral follicle populations measured after estrus synchronization in nellore cattle. Animals (Basel) 10:1185. https://doi.org/10.3390/ ani10071185.

Häggman, J., J. M. Christensen, E. A. Mäntysaari, and J. Juga. 2019. Genetic parameters for endocrine and traditional fertility traits, hyperketonemia and milk yield in dairy cattle. Animal 13:248-255. https://doi.org/10.1017/S1751731118001386.

Ireland, J. J., G. Smith, D. Scheetz, F. Jimenez-Krassel, J. Folger, J. L. Ireland, F. Mossa, P. Lonergan, and A. C. O. Evans. 2011. Does size matter in females? An overview of the impact of the high variation in the ovarian reserve on ovarian function and fertility, utility of anti-Müllerian hormone as a diagnostic marker for fertility and causes of variation in the ovarian reserve. Reprod. Fertil. Dev. 23:1-14. https://doi.org/10.1071/RD10226.

Ireland, J. J., F. Ward, F. Jimenez-Krassel, J. L. H. Ireland, G. W. Smith, P. Lonergan, and A. C. O. Evans. 2007. Follicle numbers are highly repeatable within individual animals but are inversely correlated with FSH concentrations and the proportion of goodquality embryos after ovarian stimulation in cattle. Hum. Reprod. 22:1687-1695. https://doi.org/10.1093/humrep/dem071.

Ireland, J. L. H., D. Scheetz, F. Jimenez-Krassel, A. P. N. Themmen, F. Ward, P. Lonergan, G. W. Smith, G. I. Perez, A. C. O. Evans, and J. J. Ireland. 2008. Antral follicle count reliably predicts number of morphologically healthy oocytes and follicles in ovaries of young adult cattle. Biol. Reprod. 79:1219-1225. https://doi.org/10 .1095 /biolreprod.108.071670.

Liu, M., Y. Zhu, F. Xing, S. Liu, Y. Xia, Q. Jiang, and J. Qin. 2020. The polycomb group protein PCGF6 mediates germline gene silencing by recruiting histone-modifying proteins to target gene promoters. J. Biol. Chem. 295:9712-9724. https://doi.org/10 .1074/jbc.RA119.012121.

Livestock Improvement Coorporation. 2019. Short gestation length semen. Accessed Jan. 29, 2020. https://www.lic.co.nz/products-and -services/artificial-breeding/short-gestation-length-semen/.

Macdonald, K. A., L. R. McNaughton, G. A. Verkerk, J. W. Penno, L. J. Burton, and D. P. Berry. 2007. A comparison of three strains of Holstein-Friesian cows grazed on pasture: Growth, development, and puberty. J. Dairy Sci. 90:3993-4003. https://doi.org/10.3168/ jds.2007-0119.

Martinez, M. F., N. Sanderson, L. D. Quirke, S. B. Lawrence, and J. L. Juengel. 2016. Association between antral follicle count and reproductive measures in New Zealand lactating dairy cows maintained in a pasture-based production system. Theriogenology 85:466-475. https://doi.org/10.1016/j.theriogenology.2015.09.026.

Meier, S., B. Kuhn-Sherlock, P. Amer, J. R. Roche, and C. R. Burke. 2021b. Positive genetic merit for fertility traits is associated with superior reproductive performance in pasture-based dairy cows with seasonal calving. J. Dairy Sci. 104:P10382-10398. https://doi .org/10.3168/jds.2021-20195.

Meier, S., L. R. McNaughton, R. Handcock, P. R. Amer, P. R. Beatson, J. R. Bryant, K. G. Dodds, R. Spelman, J. R. Roche, and C. R. Burke. 2021a. Heifers with positive genetic merit for fertility traits reach puberty earlier and have a greater pregnancy rate than heifers with negative genetic merit for fertility trait. J. Dairy Sci. 104:3707-3721. https://doi.org/10.3168/jds.2020-19155.

Miglior, F., B. L. Muir, and B. J. Van Doormaal. 2005. Selection indices in Holstein cattle of various countries. J. Dairy Sci. 88:12551263. https://doi.org/10.3168/jds.S0022-0302(05)72792-2.

Mossa, F., F. Jimenez-Krassel, J. K. Folger, J. L. Ireland, G. W Smith, P. Lonergan, A. C. Evans, and J. J. Ireland. 2010. Evidence that high variation in antral follicle count during follicular waves is linked to alterations in ovarian androgen production in cattle. Reproduction 140:713-720.

Mossa, F., S. W. Walsh, S. T. Butler, D. P. Berry, F. Carter, P. Lonergan, G. W. Smith, J. J. Ireland, and A. C. O. Evans. 2012. Low numbers of ovarian follicles $\geq 3 \mathrm{~mm}$ in diameter are associated with low fertility in dairy cows. J. Dairy Sci. 95:2355-2361. https://doi .org/10.3168/jds.2011-4325.

Nagai, K., Y. Yanagawa, S. Katagiri, and M. Nagano. 2015. Fertilizability of oocytes derived from Holstein cows having different antral follicle counts in ovaries. Anim. Reprod. Sci. 163:172-178. https://doi.org/10.1016/j.anireprosci.2015.11.009.

Oliveira Júnior, G. A., D. J. A. Santos, A. S. M. Cesar, S. A. Boison, R. V. Ventura, B. C. Perez, J. F. Garcia, J. B. S. Ferraz, and D. J. Garrick. 2019. Fine mapping of genomic regions associated with female fertility in Nellore beef cattle based on sequence variants from segregating sires. J. Anim. Sci. Biotechnol. 10:97. https://doi .org/10.1186/s40104-019-0403-0.

Pryce, J., R. Woolaston, D. P. Berry, E. Wall, M. Winters, R. Butler, and M. Shaffer. 2014. World trends in dairy cow fertility. Proceedings of 10th World Congress of Genetics Applied to Livestock Production. American Society of Animal Science.

Sanderson, N., and D. Robertson. 2017. Antral follicle count of New Zealand registered Angus heifer ovaries and the correlation with fertility outcomes. Pages 49-54 in Proceedings of the Society of Sheep and Beef Cattle Veterinarians and Deer Branch of the NZVA. New Zealand Veterinary Association.

Stegemiller, M., G. K. Murdoch, T. N. Rowan, K. M. Davenport, G. M. Becker, J. B. Hall, and B. M. Murdoch. 2021. Genome-wide association analyses of fertility traits in beef heifers. Genes (Basel) 12:1-15. https://doi.org/10.3390/genes12020217.

Veronese, A., O. Marques, R. Moreira, A. L. Belli, R. S. Bisinotto, T. R. Bilby, F. Peñagaricano, and R. C. Chebel. 2019. Genomic merit for reproductive traits. I: Estrous characteristics and fertility in Holstein heifers. J. Dairy Sci. 102:6624-6638. https://doi.org/10 $.3168 /$ jds.2018-15205.

Walsh, S. W., F. Mossa, S. T. Butler, D. P. Berry, D. Scheetz, F. Jimenez-Krassel, R. J. Tempelman, F. Carter, P. Lonergan, A. C. O. Evans, and J. J. Ireland. 2014. Heritability and impact of environmental effects during pregnancy on antral follicle count in cattle. J. Dairy Sci. 97:4503-4511. https://doi.org/10.3168/jds .2013-7758.

Wathes, D. C., G. E. Pollott, K. F. Johnson, H. Richardson, and J. S. Cooke. 2014. Heifer fertility and carry over consequences for life time production in dairy and beef cattle. Animal 8:91-104. https: //doi.org/10.1017/S1751731114000755.

Zhou, X., and M. Stephens. 2012. Genome-wide efficient mixed model analysis for association studies. Nat. Genet. 44:821-824. https:// doi.org/10.1038/ng.2310.

\section{ORCIDS}

T. M. Grala $\odot$ https://orcid.org/0000-0001-9897-8194 M. D. Price ๑ https://orcid.org/0000-0002-7435-8764

B. Kuhn-Sherlock @ https://orcid.org/0000-0002-1890-0301

C. R. Burke $\odot$ https://orcid.org/0000-0003-3868-8675

S. Meier ๑ https://orcid.org/0000-0002-4386-7734 